\title{
ANALISA GALIAN BERDASARKAN METODE ELEMENT HINGGA
}

\author{
Lisa Fitriyana \\ Program Studi Teknik Sipil, Fakultas Teknik, Universitas Islam Sultan Agung \\ fitriyanalisa@gmail.com \\ Reki Arbianto \\ Program Studi Teknik Sipil Fakultas Teknik Universitas Tunas Pembangunan Surakarta \\ rekiarbianto@gmail.com
}

\begin{abstract}
Abstrak
Kawasan Simpang lima aka dibuat underpass sebagai salah satu usaha mengurai kemacetan. Pembuatan underpass dilakukan dengan metode galian. Hal penting yang harus diperhatikan dalam pekerjaan galian adalah kestabilan dinding penahan tanah. Dalam penelitian ini, lokasi penelitian di laksanakan di kawasan Simpang Lima semarang. Metode pengambilan data berupa data lapangan yaitu bor mesin dan data lab. Data Bor mesin diperoleh 3 tiitk dengan kedalaman bor sampai $40 \mathrm{~m}$. Metode analisis digunakan yaitu analisis dengan metode elemen hingga dengan software Plaxis. Metode galian dilakukan secara bertahap yaitu terdiri 4 tahap dan elevasi MAT harus berada dibawah elevasi galian rencana. Hasil analisis memperlihatkan bahwa kestabilan dinding penahan tanah galian bisa tercapai dengan memberi tiang pancang sebagai dinding penahan tanah dan menambah perkuatan dengan angkur. Selain beban bangunan, juga di analisis beban gempa. PGA yang digunakan yaitu 0,1 (daerah semarang) dan interval waktu 10 detik. Dari hasil analisis diperoleh bagunan kuat dan aman dari kerusakan.
\end{abstract}

Kata kunci: galian, metode elemen hingga, beban bangunan, beban gempa.

\begin{abstract}
Simpang Lima area will be underpassed as an effort to unravel traffic jams. The underpass is made using the excavation method. The important thing that must be considered in excavation work is the stability of the retaining wall. In this study, the location of the study in the Simpang Lima area of Semarang. The method of taking data in the form of field data, namely drilling machines and lab data. Data Drill machine obtained 3 points with a drill depth of up to $40 \mathrm{~m}$. The analytical method used is the analysis with the finite element method with Plaxis software. The excavation method is carried out in stages, consisting of 4 stages and the elevation of the MAT must be below the elevation of the excavated plan. The analysis shows that the stability of the excavation retaining wall can be achieved by providing piles as retaining walls and adding reinforcement with anchor. In addition to building loads, earthquake load analysis is also analyzed. The PGA used is 0.1 (Semarang area) and a 10 second time interval. From the analysis results, it is obtained that the building is strong and safe from damage.
\end{abstract}

Keywords: excavation, finite element method, building load, earthquake load. 


\section{PENDAHULUAN}

Pemerintah Kota (Pemkot) Semarang berencana mengubah wajah Simpang Lima Semarang menjadi sebuah kawasan yang ramah lingkungan dan warga dengan membangun underpass. Pembangunan underpass dinilai akan memiliki manfaat yang sangat besar seperti salah satunya mengurai kemacetan. Selain itu juga akan bermanfaat dari sisi komersil dimana secara ekonomi nantinya bagi para PKL dan masyarakat yang berdagang di seputar Simpang Lima bisa terlokalisasi. Di mana nantinya ada komplek PKL underground yang berada di basement underpass Simpang Lima.

Konsep pembangunan underpass yaitu galian dibawah tanah. Dalam pelaksanaan galian yang harus diperhatikan adalah kestabilan dinding galian. Plaxis adalah salah satu program aplikasi komputer berdasarkan metode elemen hingga dua dimensi yang digunakan secara khusus untuk menganalisis deformasi dan stabilitas untuk berbagai aplikasi dalam bidang geoteknik.

\section{METODE PENELITIAN}

Data penelitian diambil dari data lapangan yaitu 3 titik data bor mesin sampai kedalaman $40 \mathrm{~m}$ dan data laboratorium yang terdiri dari data properties tanah.

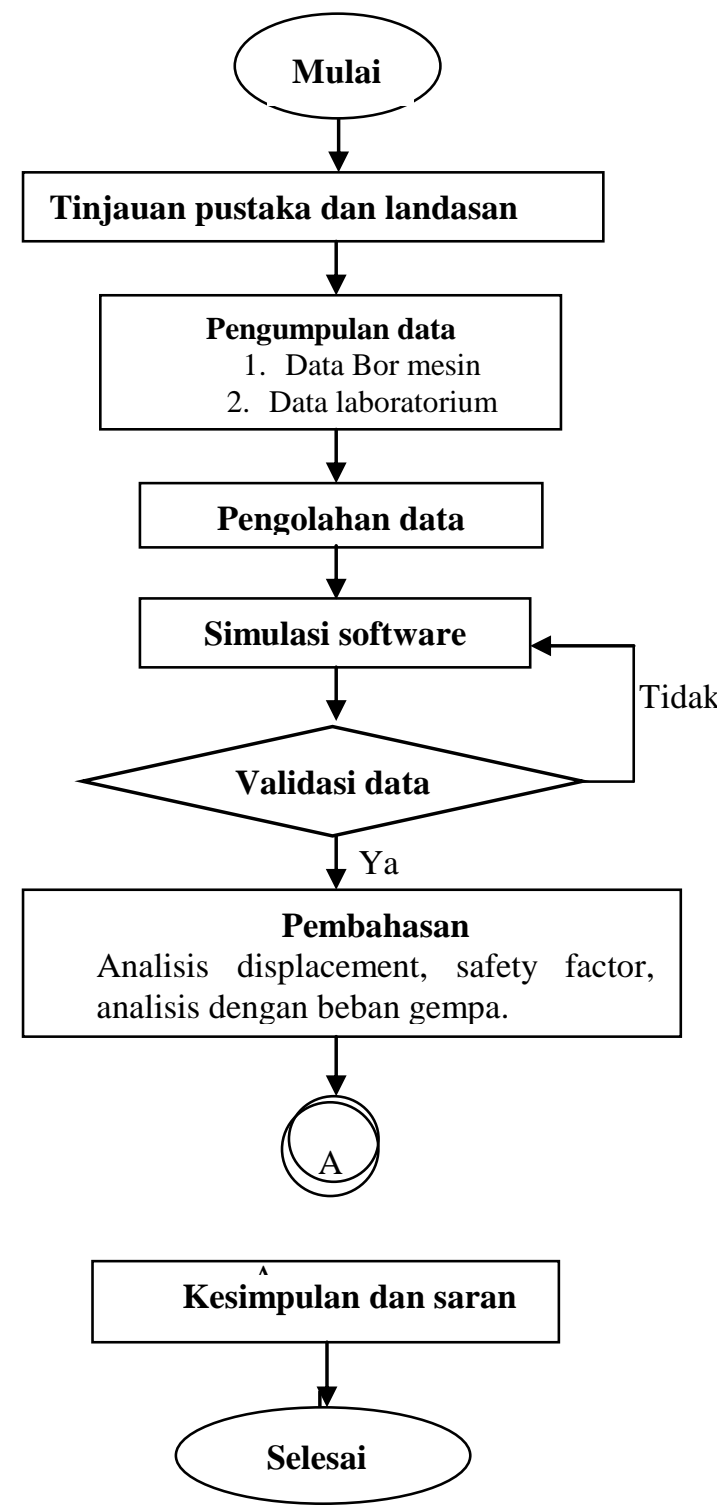

Gambar 2.1 Bagan alir penelitian

\section{HASIL PEMBAHASAN}

\subsection{Profil melintang tanah}

Gambar 3.1 menujukkan profil melintang tanah. Profil melintang dibuat berdasarkan data Bor mesin. 


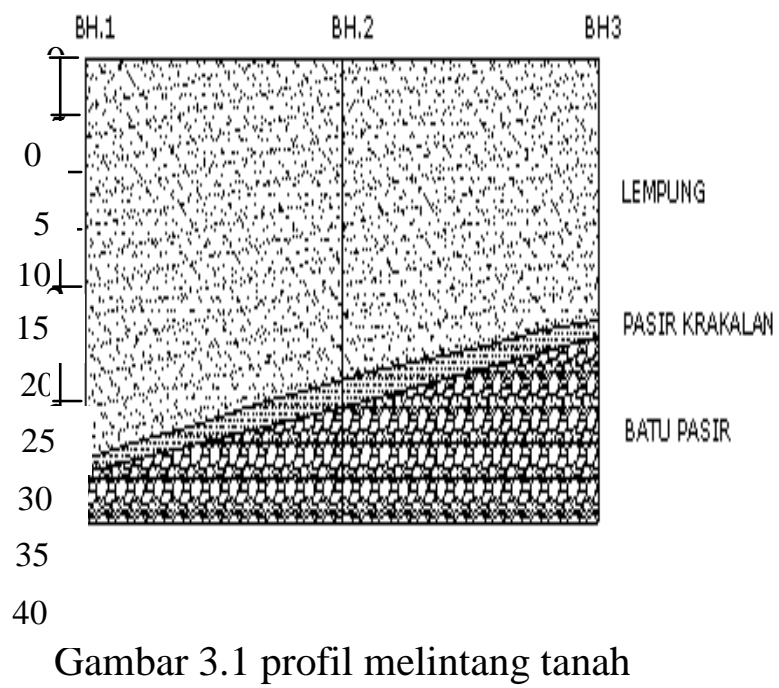

\subsection{Parameter Tanah}

Plaxis merupakan program komputer bidang geoteknik yang berdasarkan prinsip metoda elemen hingga. Program ini berbasis window (windows basic) sehingga memudahkan pengguna untuk melakukan interaksi dengan interface dan input. Proses input dapat dilakukan secara grafis dengan penggambaran sederhana seperti pada penggambaran Autocad atau model grafis lainnya. Proses pemasukan data yang sederhana ini memungkinkan proses yang cepat dari permodelan element hingga yang kompleks (Muntohar, 2009). Parameter hasil data tanah dari hasil uji Lab. dapat dilihat pada Tabel 3.1.

Tabel 3.1 Parameter tanah hasil uji Lab

2. Persiapan sampel

3. Pengujian pengembangan tanah arah aksial dan lateral dengan variasi diameter; $4,5 \mathrm{~cm}$ dan $5,7 \mathrm{~cm}$, tinggi sampel; $2 \mathrm{~cm}$ dan $2,5 \mathrm{~cm}$, dan tebal membran; 0,5 $\mathrm{mm}$ dan $0,7 \mathrm{~mm}$.

4. Persiapan sampel

5. Pengujian pengembangan tanah arah aksial dan lateral dengan variasi diameter; $4,5 \mathrm{~cm}$ dan $5,7 \mathrm{~cm}$, tinggi sampel; $2 \mathrm{~cm}$ dan $2,5 \mathrm{~cm}$, dan tebal membran; 0,5 $\mathrm{mm}$ dan $0,7 \mathrm{~mm}$.

\subsection{Analisis pekerjaan galian dengan Plaxis}

- Lebar geometri $100 \mathrm{~m}$

- Dibuat secent pile kedalaman 36 m dengan diameter $100 \mathrm{~cm}$ (kedalaman tanah keras $-36 \mathrm{~m}$ )

- Dibuat tahap galian dalam 4 tahap (jika sudah memakai secent pile, tahapnya menyesuaikan parameter tanah, jika parameter tanah kecil dibuat tidak lebih > $5 \mathrm{~m}$ ), disini d buat tahap galian jd 4 tahap dengan kedalaman $4 \mathrm{~m}, 4 \mathrm{~m}, 3 \mathrm{~m}, 3 \mathrm{~m} /$ tahap

- Ditambah Ground angkur sebagai perkuatan, diameter bar angkur 35,8 $\mathrm{mm}$, panjang angkur dengan kemiringan sudut $40^{\circ}$ adalah $17,2 \mathrm{~m}$. Pemasangan ground angkur di secent pile (-1,5 m, 7,5 m, dan -12 m arah vertikal)

- Di buat pondasi kedalaman $36 \mathrm{~m} \mathrm{dg}$ jarak $5 \mathrm{~m}$ pada lokasi proyek

- Ditambahkan beban alat berat (beban merata) $9 \mathrm{kN} / \mathrm{m} 2$



Gambar 3.2 Model Geometri pada Plaxis 2D

Hasil keluaran pada plaxis berupa displacement dan angka aman, seperti yang terlihat pada gambar berikut. 


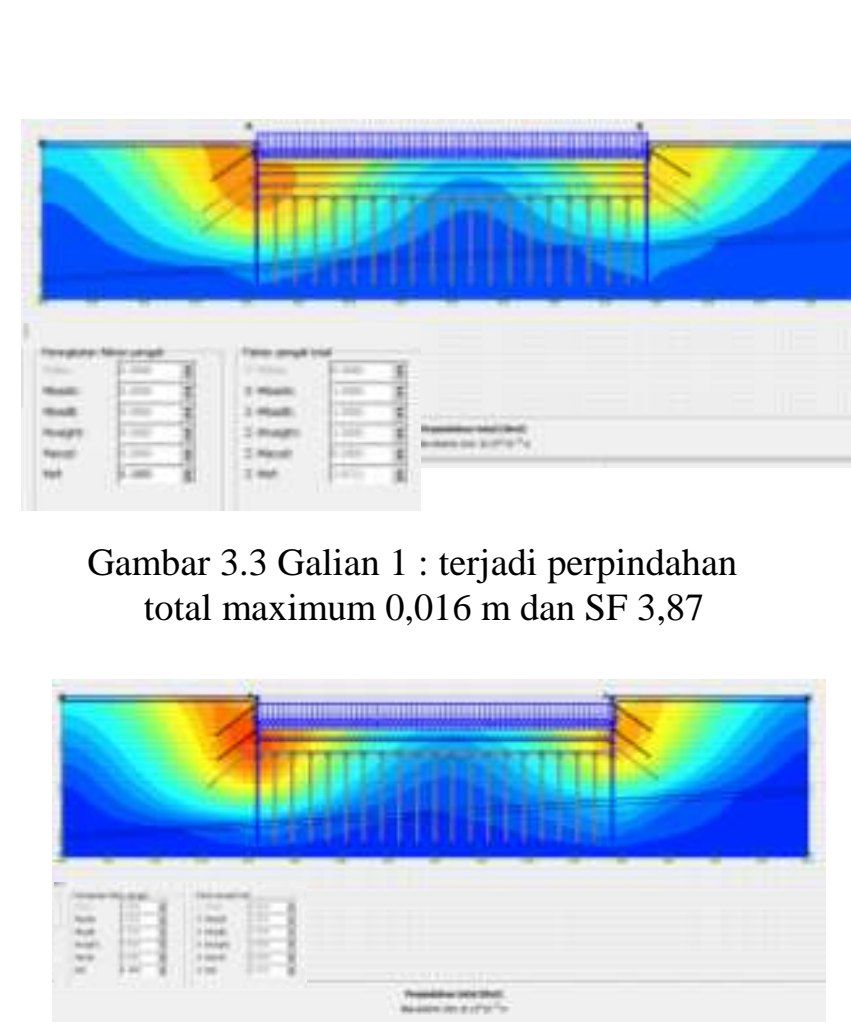

Gambar 3.4 Galian 2 : terjadi perpindahan total maximum 0,016 $\mathrm{m}$ dan SF 2,09

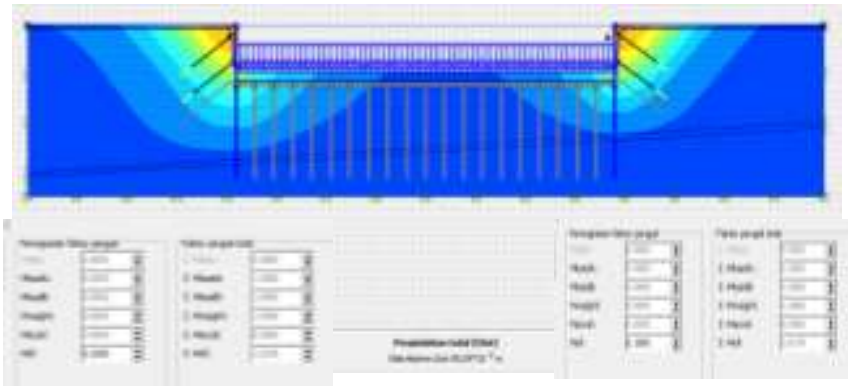

Gambar 3.5 Galian 3 : terjadi perpindahan total maximum $0,09 \mathrm{~m}$ dan SF 1,55

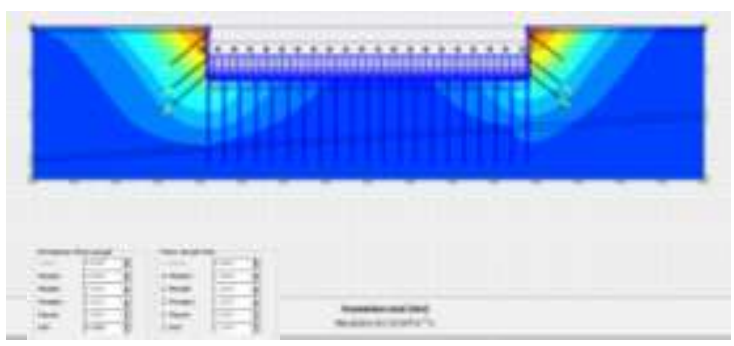

Gambar 3.6 Galian 4 : terjadi perpindahan total maximum $10,7 \mathrm{~cm}$ dan SF 2,24

\subsection{Analisis bangunan dengan beban gempa}

- Lebar geometri $100 \mathrm{~m}$ (Bangunan), tinggi bangunan dari basement $4 \mathrm{~m}$, 5m, 5m, jarak antar kolom $5 \mathrm{~m}$

- Beban diatas bangunan (rencana lapangan) $=17 \mathrm{kN} / \mathrm{m} 2$

- Dibuat secent pile kedalaman $36 \mathrm{~m}$ dengan diameter $100 \mathrm{~cm}$ (kedalaman tanah keras - $36 \mathrm{~m}$ )

- $\quad$ Di buat pondasi diameter D60 sebanyak 4 buah/pile cap sampai kedalaman 36 $\mathrm{m}$ dg jarak $5 \mathrm{~m}$ (panjang tiang $22 \mathrm{~m}$ )

- Ditambah Ground angkur sebagai perkuatan, diameter bar angkur 35,8 $\mathrm{mm}$, panjang angkur dengan kemiringan sudut $40^{\circ}$ adalah $15 \mathrm{~m}$

- Tebal Pelat Lantai $50 \mathrm{~cm}$

- Dimensi kolom $80 \mathrm{~cm}$



Gambar 3.7 Model Geometri Plaxis 2D dengan beban bagunan

Input pada beban dinamik yang digunakan adalah PGA 0,1 (area semarag) dan interval waktu getar yaitu 10 t. Selain PGA dan waktu getar juga menginput berkas 225a.smc (isi percepatan). Berkas 225a.smc adalah berkas yang menterjemahkan beban dinamik (www.manualplaxis.com). Hasil running dengan menambah beban dinamik dapat dilihat pada Gambar 3.8 




Gambar 3.8 Beban dinamik : terjadi perpindahan total maximum $0,248 \mathrm{~m}$ dan SF 3,81

\section{KESIMPULAN DAN SARAN}

\subsection{Kesimpulan}

1. Setiap tahap galian dinyatakan aman dari keruntuhan terlihat dari nilai $\mathrm{SF}>1,5$ setiap tahap galian :

- Galian 1, displacement 0,016 m dan SF 3,87

- Galian 2, displacement 0,016 m dan SF 2,09

- Galian 2, displacement 0,09 m dan SF 1,55

- Galian 4, displacement 10,7 cm dan SF 2,24

2. Analisis bangunan dengan beban gempa diperoleh perpindahan total maximum $0,248 \mathrm{~m}$ dan SF 3,81

\subsection{Saran}

- Selama Proses galian diperlukan di pasang alat inklinometer untuk melihat jika terjadi pergerakan tanah pada saat galian (sebagai savety untuk pekerja)

- Sebelum angkur di pasang :

o dilakukan uji tarik di laboratorium (menentukan mutu baja)

o dilakukan uji Pull Out Test (uji tarik di lapangan untuk ground anchor)

\section{DAFTAR PUSTAKA}

Hardiyatmo, CH. 2010. “Fondasi II”. Gamma Press. Yogyakarta.

Muntohar, Agus Setyo. 2009. "Modul Plaxis". UMY : Yogyakarta.

www.manualplaxis.com 